\title{
Photosensitivity of the Bacterial
} Pigment Cycloprodigiosin Enables Settlement in Coral Larvae - Light as an Understudied Environmental Factor

OPEN ACCESS

Edited by:

Daniel Wangpraseurt University of California, San Diego, United States

Reviewed by:

Maggy Nugues,

Université de Sciences Lettres de Paris, France

Tom Shlesinger,

Florida Institute of Technology,

United States

*Correspondence:

Matthias Y. Kellermann kellermann.matthias@gmail.com

Peter J. Schupp peter.schupp@uni-oldenburg.de

Specialty section: This article was submitted to

Coral Reef Research,

a section of the journal Frontiers in Marine Science

Received: 28 July 2021 Accepted: 11 October 2021 Published: 29 October 2021

Citation:

Petersen L-E, Kellermann MY, Nietzer S and Schupp PJ (2021)

Photosensitivity of the Bacterial Pigment Cycloprodigiosin Enables Settlement in Coral Larvae-Light as

an Understudied Environmental

Factor. Front. Mar. Sci. 8:749070. doi: 10.3389/fmars.2021.749070

\author{
Lars-Erik Petersen ${ }^{1}$, Matthias Y. Kellermann ${ }^{1 *}$, Samuel Nietzer ${ }^{1}$ and Peter J. Schupp ${ }^{1,2 *}$ \\ 1 Institute for Chemistry and Biology of the Marine Environment (ICBM), School of Mathematics and Science, \\ Carl-von-Ossietzky University Oldenburg, Oldenburg, Germany, ${ }^{2}$ Helmholtz Institute for Functional Marine Biodiversity \\ at the University of Oldenburg (HIFMB), Oldenburg, Germany
}

The survival of coral reefs largely depends among other factors on the recruitment of a new generation of coral individuals that are more adapted to a rapidly changing climate and other anthropogenic stressors (e.g., pollution, sedimentation). Therefore, a better understanding of the coral settlement process, the molecules involved as well as crucial environmental drivers that control settlement success are needed. In this study, we identified a novel settlement inducer for the brooding scleractinian coral Leptastrea purpurea and highlight the importance of light for the settlement process. Crude extract of the red-pigmented bacterium Pseudoalteromonas rubra reliably triggered attachment and metamorphosis in $L$. purpurea larvae in less than $24 \mathrm{~h}$. Prodigiosin (II) and the two derivatives, cycloprodigiosin (I) and 2-methyl-3-hexyl prodiginine (III) were isolated and structurally elucidated from the crude extract of P. rubra. We demonstrated that the photosensitive pigment cycloprodigiosin (I) was the responsible compound for attachment and metamorphosis in L. purpurea larvae. Under the tested light regimes (i.e., darkness, constant light and a dark-light alternation), cycloprodigiosin (I) triggered approximately $90 \%$ settlement at a concentration of $0.2 \mu \mathrm{g}$ $\mathrm{mL}^{-1}$ under a $12 \mathrm{~h}$ alternating dark-light cycle, mimicking the light-flooded coral reef environment. Our findings enable for the first time a mechanistic understanding of the light-dependent larva to polyp transformation by discovering the novel bacterial settlement cue cycloprodigiosin and its photosensitivity as a determining factor for coral settlement.

Keywords: coral reproduction, marine bacterial biofilms, photochemistry, planula larvae, morphogen, secondary metabolites, chemical signaling

\section{INTRODUCTION}

The survival of coral reefs, which are severely threatened by global warming, depends among other factors on the recruitment of new generations of coral individuals. The coral recruitment process can be divided into three important steps: (i) the development of competent larvae within the coral (brooding corals) or in the water column (spawning corals), (ii) the settlement process of dispersed competent larvae (subclassified into attachment and metamorphosis) onto suitable substrates, and 
finally (iii) the survival of juvenile corals, reaching the adult life stage (Ritson-Williams et al., 2009). Since the survival of juvenile corals is likely influenced by the type of substrate chosen for settlement (Harrington et al., 2004; Ritson-Williams et al., 2010), finding suitable environmental conditions (including the ideal settlement spot) may likely be the most critical step within the coral recruitment process. The attachment and subsequent metamorphosis of coral larvae are, for most species, triggered by settlement-inducing cues. These inductive cues can be of physical, biological and/or chemical nature conveying crucial information about the settlement habitat. Known cues include for example surface structure properties (Nozawa, 2008; Doropoulos et al., 2016) but also audiological signals, as larvae of the Caribbean reef building coral Montastraea faveolata were reported to detect and respond to reef sound (Vermeij et al., 2010). Furthermore, spectral cues, such as light intensity but also its quality, have been reported to affect larval behavior and habitat selection for both brooding and spawning coral species (Mundy and Babcock, 1998; Gleason et al., 2006; Yusuf et al., 2019). Color, as a function of light occurring from an object, was reported to influence coral larval settlement as well, suggesting that coral larvae feature light-sensory capabilities, and that settlement behavior may be photosensitive to photosynthetically active radiation (PAR, 400$700 \mathrm{~nm}$; Mason et al., 2011; Strader et al., 2015; Foster and Gilmour, 2016). In contrast, highly energetic light with shorter wavelengths such UVB (i.e., $280-320 \mathrm{~nm}$ ) showed a negative effect on the settlement and survival of coral larvae from different scleractinian species (Gleason and Wellington, 1995; Kuffner, 2001; Wellington and Fitt, 2003).

However, other coral settlement studies have focused on biological settlement substrates and their respective chemical compounds that are thought to signal habitat suitability. Particularly, crustose coralline algae (CCA) are a well-recognized and potent settlement substrate for larvae of many coral species that settle in response to either live CCA (Morse et al., 1988; Price, 2010; Ritson-Williams et al., 2014) or organic extracts of CCA (Heyward and Negri, 1999; Harrington et al., 2004; Kitamura et al., 2009; Da-Anoy et al., 2017). Furthermore, microbial biofilms, covering the surface of living CCA and other marine hard substrata, were also reported to be potent inducers of coral larvae settlement. That is, larvae of scleractinian corals have been found to selectively settle on (i) natural biofilms, containing a variety of epibiotic bacteria and microalgae (Webster et al., 2004; Erwin et al., 2008), but also (ii) on bacterial monospecies biofilms associated with CCA (Negri et al., 2001; Petersen et al., 2021). Meanwhile, the chemical settlement-inducing compounds produced by CCA and/or their associated microorganisms have often been scarcely described and only a few of those have been fully purified, characterized and in turn were linked to a defined biological source. For example, Morse and Morse (1991) demonstrated that a water insoluble cue isolated from decalcified CCA induces settlement in a coral species from the family Agariciidae. This chemical morphogen was suggested to contain a sulfated glycosaminoglycan; however, a definite chemical characterization of the latter chemical compound was not provided and thus its putative role as inducer for coral larval settlement remained vague. More recently, (Tebben et al., 2015) isolated fractions of an organic extract from a CCA, which induced both, attachment and metamorphosis (full settlement) in Acropora millepora larvae at equivalent concentrations present in live CCA. Their semi-purified fractions contained mainly two classes of CCA-derived cell wall-associated compounds, called glycoglycerolipids and polysaccharides. Another morphogenic compound is the bromotyrosine derivative 11-deoxyfistularin3 , which was isolated from CCA in Okinawa, Japan. 11deoxyfistularin-3 induced low levels of metamorphosis in larvae of the stony coral Pseudosiderastrea tayami, but when provided in combination with isolated CCA pigments $(\beta$ carotene, lycopene) larval metamorphosis increased to high levels (Kitamura et al., 2007). Luminaolide, a macrodiolide isolated from the CCA Hydrolithon reinboldii, was capable to enhance the metamorphosis activity in larvae of the stony coral Leptastrea purpurea, particularly when combined with a second fraction derived from the same CCA but with so far unknown chemical composition (Kitamura et al., 2009; Maru et al., 2013).

However, until today, the only bacteria-derived coral settlement compound that has been fully chemically described is tetrabromopyrrole (TBP). This secondary metabolite was isolated from a CCA associated Pseudoalteromonas sp. (Tebben et al., 2011) and induced settlement in larvae of several Caribbean stony corals, including the brooder Porites astreoides as well as the spawners Orbicella franksi and Acropora palmata (Sneed et al., 2014). Further studies on the ecological relevance of TBP in the coral settlement process revealed that this compound often induced metamorphosis without prior attachment in several Indo-Pacific coral species (Acropora millepora, A. tenuis, A. globiceps, A. surculosa, and Leptastrea purpurea), a premature morphogenic process that is likely fatal to larvae (Tebben et al., 2015). Besides naturally derived settlement compounds from CCA or their associated bacteria, several neurotransmitters have also been reported to induce metamorphosis and even full settlement in coral larvae. GLW-amide neuropeptides are known to induce metamorphosis in larvae of the scleractinian corals Acropora tenuis and A. palmata (Iwao et al., 2002; Erwin and Szmant, 2010; Grasso et al., 2011), while the neuroactive compounds dopamine, epinephrine and glutamic acid induced moderate levels of settlement in Leptastrea purpurea larvae (Moeller et al., 2019).

These discoveries gave first insights into the broad range of morphogenic cues and further studies have proven the potential of particular microbial extracts in coral settlement (Negri et al., 2001; Tebben et al., 2011, 2015). However, a better understanding of biomolecules and environmental drivers involved in coral settlement is a necessity to identify potent settlement compounds that may find application in coral aquaculture and reef restoration projects. In this study, larval attachment and metamorphosis were investigated in response to a combination of different bacteria-derived compounds and light regimes (i.e., light, darkness and its combinations). In continuation of our research interest into the settlement process of stony corals (Kitamura et al., 2009; Maru et al., 2013; Nietzer et al., 2018; Moeller et al., 2019; Petersen et al., 2021), we used the brooding scleractinian coral $L$. purpurea that is known to release 
larvae on a daily basis (Nietzer et al., 2018). Among 56 isolated bacterial strains [derived from the tropical CCA Hydrolithon reinboldii; (Petersen et al., 2021)] only the ethanol crude extract of the highly pigmented Pseudoalteromonas rubra strain \#1783 showed promising results with settlement of $L$. purpurea larvae. A further bioassay-guided fractionation attempt identified the reddish pigment cycloprodigiosin as the bioactive molecule that triggered the light dependent transformation of pelagic L. purpurea larvae to benthic juvenile corals at high levels.

\section{MATERIALS AND METHODS}

\section{Isolation and Identification of Pseudoalteromonas rubra \#1783}

Pseudoalteromonas rubra \#1783 was originally isolated from crustose coralline algae (Hydrolithon reinboldii) that were collected between April and July 2010 in Luminao, Guam $\left(13^{\circ} 27^{\prime} 53.57^{\prime \prime} \mathrm{N}, 144^{\circ} 38^{\prime} 54^{\prime \prime} \mathrm{E}\right)$. Isolation and phylogenetic identification of strain \#1783 and other bacterial isolates were previously described by Petersen et al. (2021).

\section{Acquisition of Coral Larvae}

Initially, the parent colonies of $L$. purpurea were collected from Luminao reef, Guam, in July 2015 from which larvae were obtained and settled at the University of Guam Marine Laboratory, Guam (USA). The coral recruits were then reared for 4 months and subsequently transported to the aquarium facilities of the ICBM-Terramare in Wilhelmshaven, Germany (CITES 15US62023B/9). After reaching maturity at the age of 2 years, these colonies started to release planulae and allow a steady collection of larvae in our in-house aquarium. The research aquarium is run with artificial seawater (Pro-Reef salt, Tropic Marin, Dr. Biener GmbH, Wartenberg, Germany) that allows maximum control of water chemistry and composition. L. purpurea is a brooding coral that releases competent larvae on a daily basis. Since larvae of $L$. purpurea range up to $1 \mathrm{~mm}$ in length, no magnification was needed for collection. As stated in Nietzer et al. (2018), L. purpurea planulae produce a green fluorescent protein (GFP), which enables convenient collection of larvae by using fluorescent blue light (460$480 \mathrm{~nm}$ wavelengths) and a yellow barrier filter. Thus, the coral larvae appear in a greenish color and can be better differentiated from other abiotic and biotic matter. The larvae were picked with a pipette and collected in small glass flasks for future experiments. Larvae could be stored in filtered artificial seawater (FASW, also made with Tropic Marin Pro-Reef salt) for several days if a steady access to oxygen was enabled and the FASW exchanged on a daily basis to ensure high quality conditions. By using artificial seawater, we can be certain that environmental conditions remained constant throughout larval experiments.

\section{Bioassay-Guided Isolation of Pure Compounds}

The settlement-inducing compound of the inductive bacterial strain $P$. rubra \#1783 was isolated by bioassay-guided fractionation. For that, 50 large $\mathrm{MB}$ (marine broth) agar plates $\left(14 \mathrm{~cm}\right.$ diameter) were inoculated in the dark at $27^{\circ} \mathrm{C}$ (Certomat BS-1, Sartorius AG, Göttingen, Germany) with a $24 \mathrm{~h}$ old liquid stock culture of $\# 1783$ also grown at $27^{\circ} \mathrm{C}$ in $\mathrm{MB}$ medium. After $24 \mathrm{~h}$, the bacterial lawn was carefully scraped off all 50 plates and the resulting cell paste was extracted three times with $100 \%$ ethanol (EtOH). For each extraction, the cell paste was homogenized at $12,000 \mathrm{rpm}$ for $30 \mathrm{~s}$ using a T25 Ultra Turrax (IKA Werke GmbH \& Co., KG, Staufen im Breisgau, Germany). Each homogenized crude extract was then filtered through $3 \mathrm{hw}$ cellulose filter paper (Sartorius AG, Göttingen, Germany) and the filtrate collected and dried using a speed-vac system (Martin Christ Gefriertrocknungsanlagen $\mathrm{GmbH}$, Osterode am Harz, Germany). The combined cell-free extract was reconstituted in methanol/water (9:1) and subsequently separated by liquidliquid partitioning using solvents with different polarities, including $n$-hexane, dichloromethane (DCM), ethyl acetate and finally water (see Figure 1A). Resulting fractions were tested in the settlement assays for inductive activity (see next paragraph). The active DCM fraction was further subjected to solid-phase extraction (SPE) using a reverse-phase $\mathrm{C}_{18}$-flash vacuum column (Supelclean LC-18, 6 mL tubes, Supelco, Sigma-Aldrich, St-Louis, MO, United States) and sequentially eluted with Milli-Q water from an Arium 611DI ultrapure water system (Sartorius AG, Göttingen, Germany) and acetonitrile (ACN) in ratios of 70:30 (Fr. 1), 60:40 (Fr. 2), 50:50 (Fr. 3), 40:60 (Fr. 4), 30:70 (Fr. 5), 20:80 (Fr. 6), 10:90 (Fr. 7), 100\% ACN (Fr. 8), ACN/MeOH 50:50 (Fr. 9), $100 \% \mathrm{MeOH}$ (Fr. 10) and 100\% DCM (Fr. 11). The resulting eleven SPE fractions were again tested for their settlementinducing activity. SPE fraction 8 (100\% ACN; see Figure 1A) induced settlement and was further purified on an Agilent 1260 Infinity HPLC-DAD system (Agilent Technologies, Inc., Santa Clara, United States). HPLC separation included dissolving SPE Fr. 8 in Ultra Performance Liquid Chromatography (UPLC) grade $\mathrm{MeOH}$, filtering through a $0.2 \mu \mathrm{m}$ PTFE syringe filter and subsequently injecting $100 \mu \mathrm{L}$ of a $10 \mathrm{mg} \mathrm{mL}^{-1}$ solution onto the HPLC-DAD system. Chromatographic separation was achieved at $40^{\circ} \mathrm{C}$ using a semipreparative reverse-phase $\mathrm{C}_{18}$ column (Pursuit XRs $5 \mu \mathrm{m} \mathrm{C}_{18}, 250 \mathrm{~mm} \times 10 \mathrm{~mm}$, Agilent Technologies, Inc., Santa Clara, CA, United States). The mobile phase consisted of A: $100 \%$ Milli-Q water (with $0.1 \%$ formic acid) and $\mathrm{B}: 100 \% \mathrm{ACN}$ (with $0.1 \%$ formic acid), pumped at a rate of $2.0 \mathrm{~mL} \mathrm{~min} \mathrm{~min}^{-1}$. The initial condition was $55 \%$ A held for $2 \mathrm{~min}$, followed by a linear gradient to $70 \% \mathrm{~B}$ in $88 \mathrm{~min}$. The column was then washed with $100 \% \mathrm{~B}$ for $15 \mathrm{~min}$ and subsequently returned and held for $15 \mathrm{~min}$ at the initial conditions (55\% eluent A) to equilibrate the column for the following preparative run. The prodigiosin-derivatives were monitored using a UV-VIS detector set at a wavelength of $536 \mathrm{~nm}$ (ChemStation for LC 3D systems) and target compounds were each manually isolated from Fr. 8.

\section{Structure Elucidation via UPLC-DAD-MS/MS and Nuclear Magnetic Resonance Spectroscopy}

High resolution single mass spectra (MS) and MS/MS spectral data of pure compounds were measured on an ACQUITY UPLC H-Class System (Waters Co., Milford, MA, United States) 
A

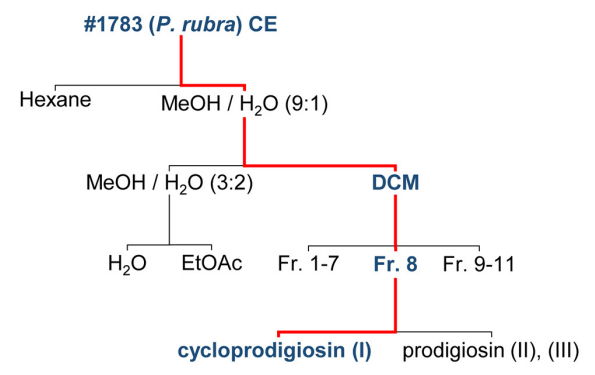

B

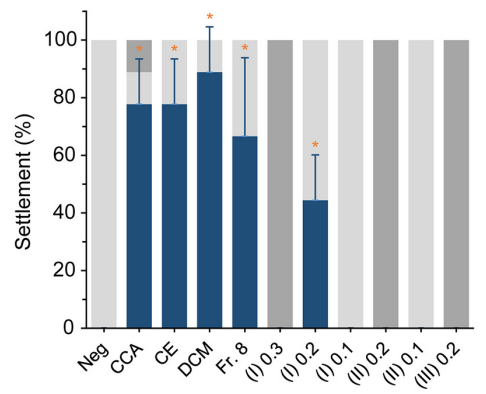

FIGURE 1 | Extraction of settlement cues from Pseudoalteromonas rubra \#1783 and initial evaluations of their settlement-inducing activity toward Leptastrea purpurea coral larvae. (A) Flow scheme of secondary metabolite extraction from Pseudoalteromonas rubra \#1783. The bold blue font as well as the red line follows the path of settlement-inducing activity within each crude extract/fraction/compound. (B) Response of Leptastrea purpurea larvae after $48 \mathrm{~h}$ to different fractions of \#1783 under unregulated light conditions (see materials and methods section for details): CE, crude extract (10 $\left.\mu \mathrm{g} \mathrm{mL}^{-1}\right)$, DCM, dichloromethane (5 $\mu \mathrm{g} \mathrm{mL}{ }^{-1}$ ), SPE, solid-phase extraction ( $C_{18}$-based, fraction 8) $\left(0.5 \mu \mathrm{g} \mathrm{mL}^{-1}\right)$, (I), cycloprodigiosin $\left(0.1,0.2\right.$, and $\left.0.3 \mu \mathrm{g} \mathrm{mL}^{-1}\right)$, (II), prodigiosin $\left(0.1 \mathrm{and} 0.2 \mu \mathrm{g} \mathrm{mL}{ }^{-1}\right)$, (III), 2-methyl-3-hexyl prodiginine $\left(0.2 \mu \mathrm{g} \mathrm{mL}^{-1}\right)$. Percentages of swimming larvae are displayed in light gray, settlement in dark blue, and dead/disintegrated larvae in dark gray. Evaporated $\mathrm{MeOH}$ and $5 \mathrm{~mL}$ of filtered artificial seawater (FASW) served as negative control (Neg). Small pieces of live CCA emerged in $5 \mathrm{~mL}$ of FASW were used as positive control. Error bars represent standard deviations of settlement. Asterisks $\left.{ }^{*}\right)$ represent significant settlement responses $(p<0.05, n=3)$.

coupled to a Synapt G2-Si HDMS high-resolution Q-ToFMS (Waters Co., Manchester, United Kingdom) equipped with a LockSpray dual electrospray ion source operated in positive (POS) ionization mode. The mass spectrometer system was controlled by MassLynx ${ }^{\mathrm{TM}}$ software (version 4.1, Waters Corporation, Milford, MA, United States). Chromatographic separation was achieved on a Waters Acquity BEH $\mathrm{C}_{18}$ column $(1.7 \mu \mathrm{m}, 2.1 \mathrm{~mm} \times 50 \mathrm{~mm})$. The Q-ToF-MS was calibrated in resolution mode over a mass-to-charge $(\mathrm{m} / \mathrm{z})$ ranging from 50 to 2,000 Dalton by using a $0.5 \mathrm{mmol} \mathrm{L}^{-1}$ sodium formate solution. For each run leucine enkephalin was used as lock mass, generating a reference ion in the positive mode [POS, $\left.(\mathrm{M}+\mathrm{H})^{+}=556.277\right]$ to ensure a mass tolerance for all MS or MS/MS experiments of less than one ppm. Mass spectral data were collected using the MS/MS or MS ${ }^{e}$ data acquisition function to simultaneously obtain information on the intact molecule (no collision energy applied) as well as their fragmentation data (collision energy ramp reaching from 15 to $75 \mathrm{eV}$ ). Analytes were eluted at a flow rate of $0.6 \mathrm{~mL} \mathrm{~min}^{-1}$ using a linear gradient of $\mathrm{H}_{2} \mathrm{O}(100 \%$, eluent $\mathrm{A})$ to acetonitrile $(\mathrm{ACN}, 100 \%$, eluent $\mathrm{B}$ ) both containing additional $0.1 \%$ formic acid. The initial condition was $100 \%$ A for $0.5 \mathrm{~min}$, followed by a linear gradient to $100 \% \mathrm{~B}$ in $19 \mathrm{~min}$. The column was then washed with $100 \%$ B for 9.5 min and subsequently returned and held for $2.9 \mathrm{~min}$ at the initial conditions ( $100 \%$ eluent A) to equilibrate the column for the following run. The column temperature was set to $40^{\circ} \mathrm{C}$. The crude extract (CE) of \#1783, the fractions of the liquid-liquid partitioning and the SPE separation as well as the major purified prodiginines (I, II, and III) were dissolved in UPLC grade $\mathrm{MeOH}$ to a final concentration of 10,1 , and $0.1 \mathrm{mg} \mathrm{mL}^{-1}$, respectively and injected onto the UPLC-DAD-MS/MS system (injection volume ranging between 0.1 to $10 \mu \mathrm{L}$ ). Both UV-VIS (200-700 nm; photodiode array detector (PAD), Waters Corp., Milford, MA, United States) and mass spectral data were evaluated using the MassLynx ${ }^{\mathrm{TM}}$ software. For identification of known compounds, datasets of the extract and fractions were compared with entries in the database Dictionary of Natural Products, MarinLit and other publicly available databases. Measured data was reconciled with database entries in matters of absorption maxima, accurate mass, MS/MS fragments and biological source. Structure elucidation of the isolated settlement cue was conducted by employing nuclear magnetic resonance (NMR) spectroscopy. ${ }^{1} \mathrm{H}$ NMR spectra were acquired using a $500 \mathrm{MHz}$ NMR spectrometer equipped with a cryoprobe (Bruker Avance DRX 500, Bruker BioSpin GmbH, Rheinstetten, Germany) and referenced to residual ${ }^{1} \mathrm{H}$ resonances present in the deuterated solvent $\left(\mathrm{CDCl}_{3}\right)$. NMR spectra received from measurements were analyzed using the program Mnova (Mestrelab Research SL). The ${ }^{1} \mathrm{H}$-NMR spectra of cycloprodigiosin (I) and prodigiosin (II) can be found in Supplementary Figures 1,2 as well as Supplementary Tables 1,2.

\section{Cycloprodigiosin Degradation Assay and Quantification on Agar Plates}

To calculate the amount of pure compound in the degradation assay, a calibration curve using $0.025,0.05,0.1,0.5,1$, 5,10 , and $25 \mathrm{ng}$ of cycloprodigiosin (I) was created (see Supplementary Figure 3). The degradation assay was performed in flat-bottom 12-well plates (TPP Techno Plastic Products AG, Trasadingen, Switzerland) and the same three different light regimes were applied as during the settlement assays: complete darkness, constant white light and $12 \mathrm{~h}$ alternating dark and light phases, starting with full darkness (see Figure 2). In total, $1 \mu \mathrm{g}$ of (I), dissolved in $\mathrm{MeOH}$, was applied onto the bottom of the respective wells. After evaporation of the solvent $\mathrm{MeOH}, 5 \mathrm{~mL}$ FASW was added to each well to recreate the conditions present in the settlement assays. Degradation of (I) under darkness and white light was measured after 0,24 , and $48 \mathrm{~h}$. Under the $12 \mathrm{~h}$ alternating dark and light rhythm, measurements were conducted after $0,12,24,36$, and $48 \mathrm{~h}$. For each light regime, time 

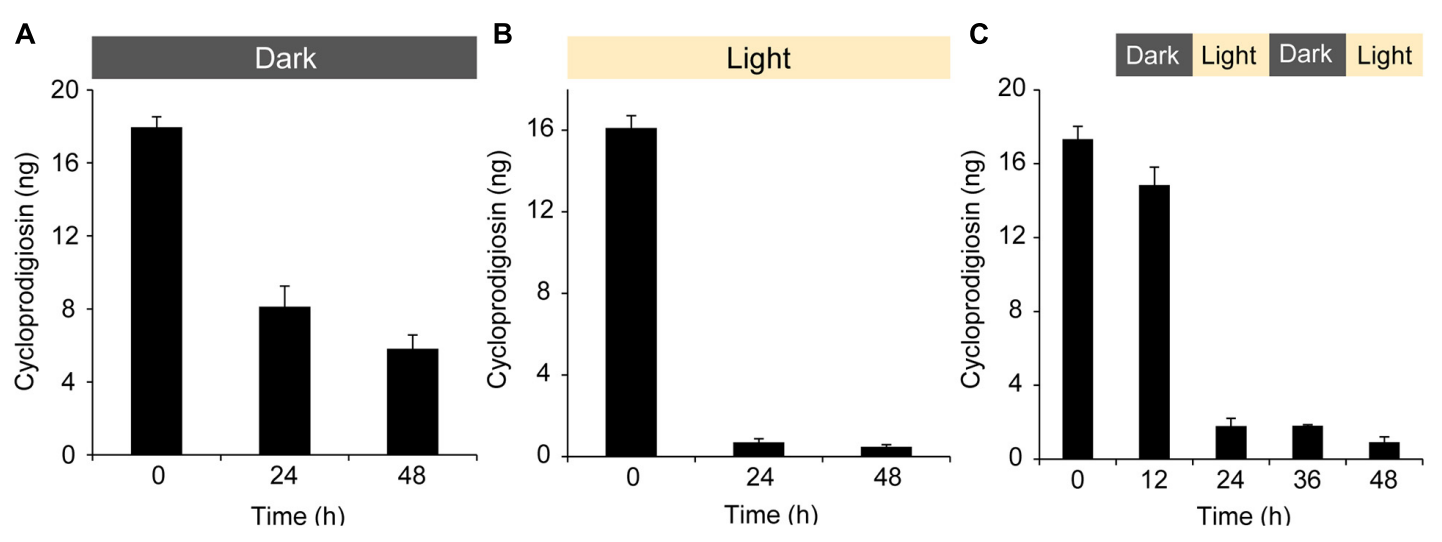

FIGURE 2 | The influence of light and its absence on the isolated pigment cycloprodigiosin (I). $1 \mu \mathrm{g}$ of (I) was added to a $5 \mathrm{~mL}$ well plate, the solvent MeOH evaporated and $5 \mathrm{~mL}$ FASW added on top of the isolated pigment. The concentration changes of (I) over $0,12,24,36$, and $48 \mathrm{~h}$ at (A) complete darkness, (B) white light and $\mathbf{( C )}$ alternating $12 \mathrm{~h}$ dark/light cycles were monitored after discarding the water and re-extracting the well plate with $200 \mu \mathrm{L}$ MeOH. $(5 \mu \mathrm{L}$ injected to the UPLC-MS).

points were sampled in triplicates. For this purpose, the $5 \mathrm{~mL}$ of FASW were removed and discarded from the respective wells and the residues of (I) were taken up in $200 \mu \mathrm{L}$ of $\mathrm{MeOH}$, off which $1 \mu \mathrm{L}$ was injected to UPLC-DAD-MS/MS (see next paragraph) to quantify the re-extracted, remaining amount of (I).

For the quantification of (I) produced by monospecific biofilms of $P$. rubra \#1783, several small MB agar plates were inoculated in the dark at $27^{\circ} \mathrm{C}$ (Certomat BS-1, Sartorius AG, Göttingen, Germany) with a $24 \mathrm{~h}$ old liquid stock culture of P. rubra \#1783 also grown at $27^{\circ} \mathrm{C}$. After $24 \mathrm{~h}$, bacterial lawn from 1,4 , and $9 \mathrm{~cm}^{2}$ agar surface was carefully scraped off all plates in triplicates (except for $9 \mathrm{~cm}^{2}$, which was only sampled once, see Supplementary Figure 4) and the resulting cell paste was further extracted as described before. The amount of (I) per 1,4 , and $9 \mathrm{~cm}^{2}$ in the resulting crude extracts was determined via a calibration curve as described above.

\section{Settlement Assays}

Crude extract (CE), dichloromethane partition (DCM), and fraction 8 (Fr.8) from the solid-phase extraction were dissolved in UPLC grade $\mathrm{MeOH}$ and brought to a concentration of $1 \mathrm{mg}$ $\mathrm{mL}^{-1}$. Cycloprodigiosin (I), prodigiosin (II) and 2-methyl-3hexyl prodiginine (III) were dissolved in UPLC grade $\mathrm{MeOH}$ and brought to a concentration of $0.1 \mathrm{mg} \mathrm{mL}^{-1}$. CE, fractions and pure compounds were tested for their ability to induce settlement in coral larvae of Leptastrea purpurea. Assays were conducted in flat-bottom 12-well plates (TPP Techno Plastic Products AG, Trasadingen, Switzerland) and the different analytes were applied to the bottom of the well. The bioassay-guided fractionation process used decreasing amounts of analytes in the settlement assays, since the concentration of target compounds increased in the respective fractions $\left(10,5\right.$ and $0.5 \mu \mathrm{g} \mathrm{mL} \mathrm{m}^{-1}$ for CE, DCM and SPE Fr. 8, respectively). Note that the tested concentrations of pure compounds (I), (II), and (III) were set according to their share in the preceding Fr. 8, pointing us toward a narrow window of $0.3,0.2$, and $0.1 \mu \mathrm{g} \mathrm{mL}^{-1}$ for (I). Compounds (II) was tested at 0.2 and $0.1 \mu \mathrm{g} \mathrm{mL}^{-1}$ while compound (III) was only tested at $0.1 \mu \mathrm{g} \mathrm{mL}^{-1}$ due to limitations in larvae availability (cf. Figure 1B). $\mathrm{MeOH}$ was used as negative control $(\mathrm{Neg})$ while small pieces of live CCA $(H$. reinboldii) served as positive control (CCA). After evaporation of the $\mathrm{MeOH}$ from the different analytes and the negative controls, $5 \mathrm{~mL}$ FASW was added to each well. This translates to final quantities of 50, 25, and $2.5 \mu \mathrm{g}$ per $5 \mathrm{~mL}$ FASW in each well for CE, DCM and Fr.8, respectively. Hence, pure compounds (I), (II), and (III) were tested at $1.5,1.0$, and $0.5 \mu \mathrm{g}$ per $5 \mathrm{~mL}$ FASW in each well. Due to limitations in larvae availability from our in-house aquarium, we added five coral larvae per well for each of the three replicates. Coral larvae used for settlement assays were not older than 5 days. Larval settlement behavior in all assays was examined under a dissecting microscope at the beginning of each experiment and after 12, 24, 36, and $48 \mathrm{~h}$. All assays were performed and kept at $27^{\circ} \mathrm{C}$ over the entire length of the experiment. Initial settlement assays with extracts of the bioassayguided fractionation approach [CE, DCM, Fr. 8 and (I), (II), (III)] were carried out in a portable incubator without light control but with a light-transmissive door (Micronic Cultura Micro Incubator, Almedica AG, Galmiz, Switzerland). Thus, they were performed under the presence and absence of natural light in the laboratory throughout the day, depending on the starting point of the experiment. Later, settlement assays were repeated with fresh coral larvae and cycloprodigiosin (I) under three distinct light regimes using an incubator with light control (Certomat BS-1, Sartorius AG, Göttingen, Germany): (A) complete darkness, (B) full white light (1929 lux, 25 PPFD) and (C) $12 \mathrm{~h}$ alternating dark and light phases, starting with full darkness ( $c f$. Figure 3). Larval behavior was differentiated into four categories: (i) swimming larvae (no reaction to the cue, Figures 4A1,2), (ii) attachment to a surface (Figures $4 \mathbf{B 1}, 2$ ), (iii) settlement (attachment and metamorphosis, see Figures 4C1,2) and (iv) dead larvae that have disintegrated. Coral larvae were designated "attached" if gentle water movements created by a pipette motion (ca. $0.5 \mathrm{~mL}$ $\mathrm{s}^{-1}, 1 \mathrm{~mm}$ diameter opening and in ca. $5 \mathrm{~mm}$ distance to the larvae) could not detach the larvae. After the development of 

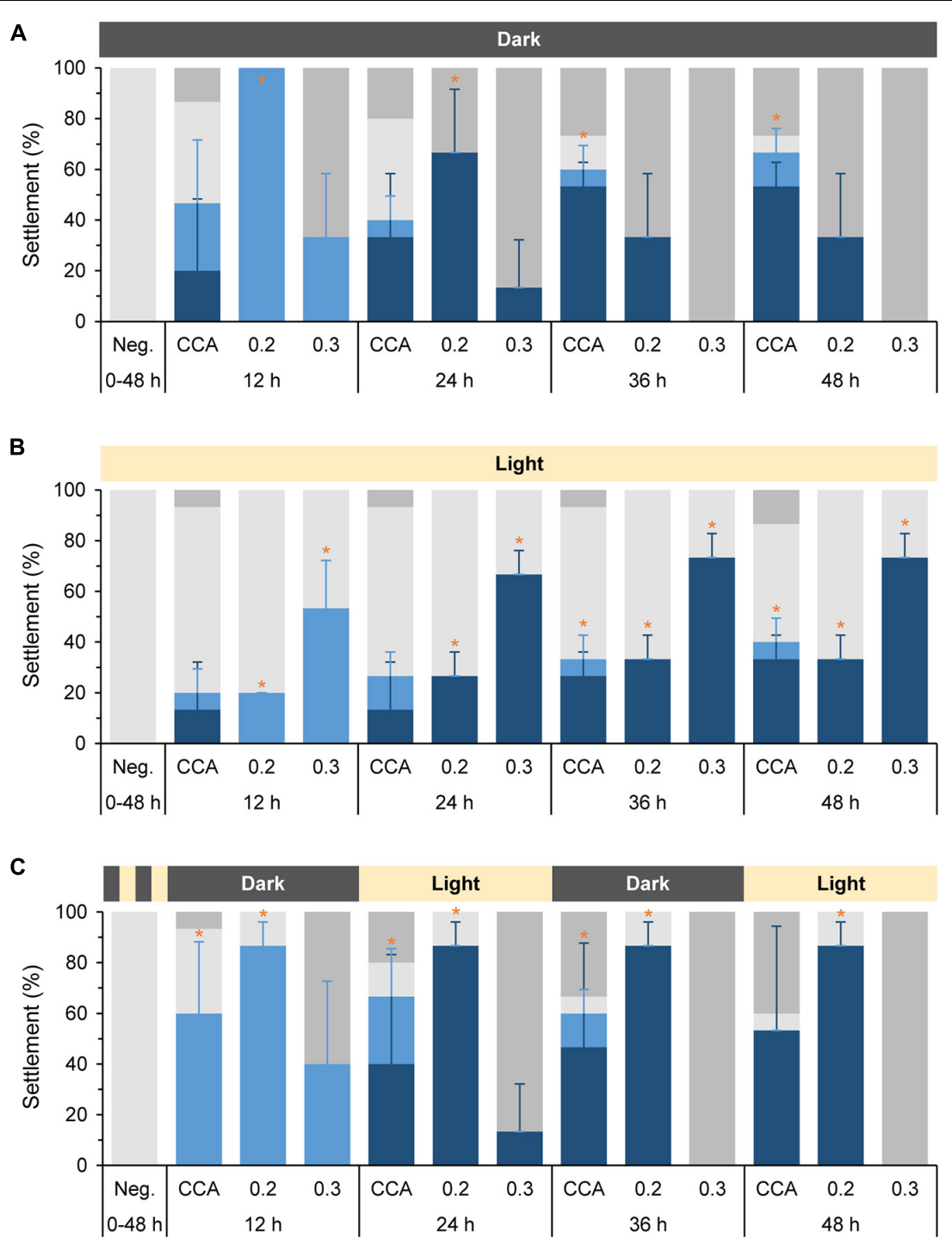

FIGURE 3 | Settlement behavior of Leptastrea purpurea larvae in response to different concentrations of cycloprodigiosin (I) and three varying light regimes. Coral larvae were exposed to (I) levels of $0.2 \mu \mathrm{g} \mathrm{mL}^{-1}$ and $0.3 \mu \mathrm{g} \mathrm{mL} \mathrm{L}^{-1}$ for 12, 24, 36, and $48 \mathrm{~h}$ in complete darkness (A), constant white light (B) and $12 \mathrm{~h}$ alternating periods of dark and light phases starting with complete darkness (C). Percentages of swimming larvae are displayed in light gray, attachment in light blue, settlement (attachment and metamorphosis) in dark blue, and dead larvae in dark gray colors. Evaporated MeOH and $5 \mathrm{~mL}$ of FASW served as negative control (Neg). Small pieces of live CCA emerged in $5 \mathrm{~mL}$ of FASW were used as positive control. Error bars represent standard deviations of settlement and attachment. Asterisks (*) represent significant settlement responses ( $p<0.05, n=3$ ).

an oral disk and clearly visible septae during the metamorphosis process, young polyps show typical "flower-like" forms. Larvae of L. purpurea were designated "settled" if both attachment and metamorphosis took place. A possible limitation of the settlement assays may be the relatively small numbers of tested coral larvae and replicates. This is due to the constant but limited availability of larvae from the brooding species L. purpurea in our in-house aquarium system.

\section{Statistical Analysis}

Since settlement behavior data were not normally distributed, all data points were tested together with the negative controls for significance (except for those whose three replicates of one treatment were all 0) using a non-parametric Kruskal-Wallis test followed by a pairwise Dunn's test with Bonferroni correction to perform multiple comparisons. Thus, the $p$-values indicate the difference between all three replicates of the different treatments (i.e., compound concentration and light regime) compared to the negative control, resulting in multiple $p$-values for all settlement experiments. Furthermore, we evaluated the effect size of our two most successful treatments by using Cohen's d. It is calculated as the difference of the means of two groups divided by their weighted pooled standard deviations. Cohen (1992) suggested effect sizes of $0.2-0.3$ being small, 0.5 being medium, and $\geq 0.8$ 


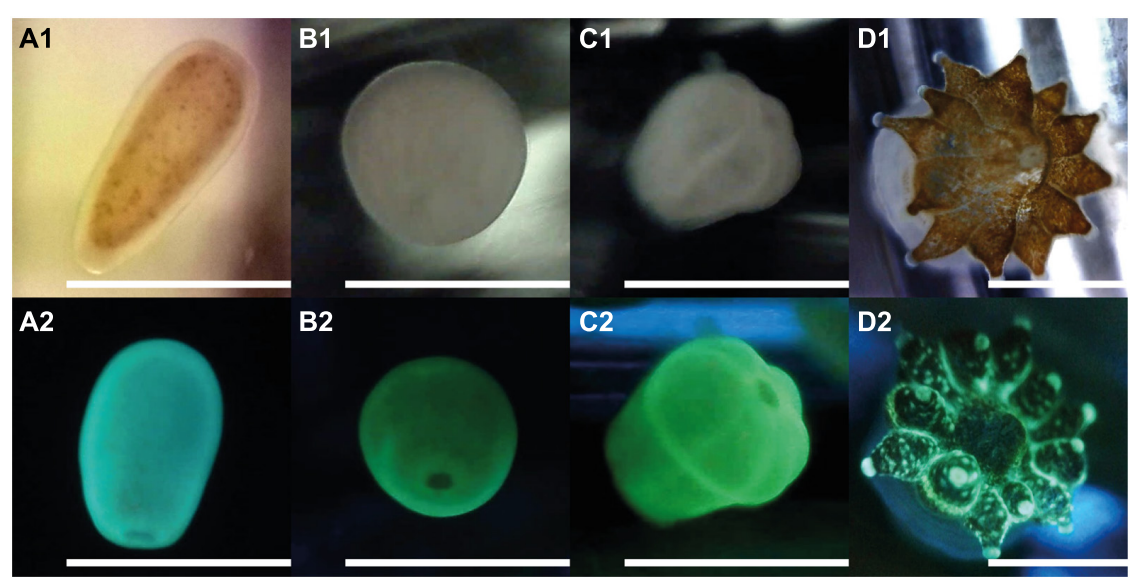

FIGURE 4 | Early life stages of Leptastrea purpurea recruits in response to cycloprodigiosin (I) and alternating dark-light phases of $12 \mathrm{~h}$ repeating intervals (starting with complete darkness). Numbers behind alphabetic characters indicate what light setting has been used: (1) was taken using a white LED light while (2) used a blue LED light (wavelength: 460-480 $\mathrm{nm}$ ) to illuminate the larva/polyp and a yellow filter was applied to capture only the red and green fluorescence emitted from the specimen. (A1,2) planula larvae; (B1,2) 12 h attached recruit; $(\mathbf{C 1 , 2 )} 48$ h attached and metamorphosed primary polyp; (D1,2) 1 month old, fully developed coral polyp of Leptastrea purpurea. Scale bar: $1.0 \mathrm{~mm}$.

being large. Statistical analysis was conducted with SPSS Statistics 26 (IBM, version 26).

\section{RESULTS}

\section{Extraction of a Secondary Metabolite From Pseudoalteromonas rubra Triggering Settlement in Leptastrea purpurea Coral Larvae}

From 30 inductive bacterial monospecies biofilms isolated from H. reinboldii (Petersen et al., 2021) only one single red pigmented strain (\#1783) produced a crude extract (CE) that induced full settlement (attachment and metamorphosis) in L. purpurea larvae at a high and significant level with a concentration of $10 \mu \mathrm{g} \mathrm{mL}^{-1}(77.8 \% \pm 15.7, p=0.034$, see Figure 1B). The CE of the nine other highly inductive strains (see Petersen et al., 2021 for details) tested at this concentration showed no settlement activity. Referencing to the Silva database, strain \#1783 shared a $99.9 \%$ similarity with its closest type strain and was therefore identified as Pseudoalteromonas rubra (Petersen et al., 2021). The settlement-inducing CE of strain \#1783 was subsequently purified using liquid-liquid partitioning (LLP), $\mathrm{C}_{18}$-based solidphase extraction (SPE), and $\mathrm{C}_{18}$-based semi-preparative highperformance liquid chromatography in combination with a diode array detector (HPLC-DAD), to isolate fractions and pure compounds that induced settlement in L. purpurea larvae. Final concentrations of all extracts tested were determined as described in the materials and methods section, which ultimately resulted in (I) concentrations ranging from 0.1 to $0.3 \mu \mathrm{g} \mathrm{mL} \mathrm{m}^{-1}$ (i.e., Figure 1A). Attachment and metamorphosis of coral larvae were usually clearly visible after $24 \mathrm{~h}$ but more pronounced after $48 \mathrm{~h}$. Thus, for the statistical analysis the status of the larvae was examined only after $48 \mathrm{~h}$ for the CE, its purified fractions as well as pure compounds (Figures 1A,B). The LLP resulted in four fractions, of which only the DCM fraction induced settlement at high and significant levels at concentrations of $5 \mu \mathrm{g}$ $\mathrm{mL}^{-1}(88.9 \% \pm 15.7, p=0.034$, see Figure 1B). The active DCM fraction was further subjected to a $\mathrm{C}_{18}$-based SPE column, resulting in 11 highly resolved fractions. One of the 11 fractions, Fr. 8, induced settlement in coral larvae at moderate-to-high, but still significant levels at $0.5 \mu \mathrm{g} \mathrm{mL}^{-1}(66.6 \% \pm 27.2, p=0.037$, see Figure 1B).

Fr. 8 was mainly composed of one group of red pigments that consisted of three major peaks (I, II, and III) and five minor peaks (IV, V, VI, VII, and VIII), all putatively belonging to the same alkaloid family, the prodiginines (cf. Table 1 and Supplementary Figure 5). Subsequently, semipreparativeHPLC separation, using a $\mathrm{C}_{18}$-based column, resulted in the isolation of compound (I), (II) and (III). Analysis of the high-resolution mass spectra of the red pigments identified $m / z 322.191\left(\mathrm{M}+\mathrm{H}^{+}\right)$for $(\mathrm{I}), m / z 324.207\left(\mathrm{M}+\mathrm{H}^{+}\right)$ for (II) and $m / z 338.223\left(\mathrm{M}+\mathrm{H}^{+}\right)$for (III). Compound (I) was identified as cycloprodigiosin, (II) as prodigiosin and (III) as 2-methyl-3-hexyl prodiginine, a close derivative of (II). Identification of compounds (I), (II) and (III) was conducted by comparing their high-resolution molecular mass of parent ions $\left(\mathrm{MS}^{1}\right)$ and their characteristic fragment ions $\left(\mathrm{MS}^{2}\right.$; cf. Supplementary Figures 6-8) via UPLC-DAD-HRMS and HRMS/MS as well as their UV/VIS absorption spectra, cf. Table 1 and Supplementary Figure 9, with literature (i.e., Setiyono et al., 2020) and entries in large public and commercially available databases (e.g., Metlin, MarinLit and Dictionary of Natural Products) for dereplication. The two most abundant pigments cycloprodigiosin (I) and prodigiosin (II) were further confirmed spectroscopically using ${ }^{1} \mathrm{H}-\mathrm{NMR}$ spectra, by comparing measured shifts with literature values (Supplementary Figures 1, 2 and Supplementary Tables 1, 2). Interestingly, we did not detect any of the above mentioned 
TABLE 1 | Dereplication of prodiginines produced by Pseudoalteromonas rubra \#1783.

\begin{tabular}{|c|c|c|c|c|}
\hline Peaks & $m / z(M+H)^{+}$ & $m / z$ product ions & $\lambda_{\max }(\mathrm{nm})$ & Identification \\
\hline \multicolumn{5}{|c|}{ MAJOR prodiginines } \\
\hline (l) & 322.191 & $307.168,292.144,146.096$ & $296,362,536$ & Cycloprodigiosin \\
\hline (II) & 324.207 & $309.184,252.113,92.050$ & 293, 369, 532 & Prodigiosin \\
\hline (III) & 338.223 & $323.199,252.114,92.050$ & $294,369,536$ & 2-methyl-3-hexyl prodiginine* \\
\hline \multicolumn{5}{|c|}{ MINOR prodiginines } \\
\hline (IV) & 296.176 & $281.152,252.113,92.050$ & n.d. & 2-methyl-3-propyl prodiginine* \\
\hline$(\mathrm{V})$ & 308.176 & $293.151,248.118,92.050$ & n.d. & n.i. \\
\hline$(\mathrm{VI})$ & 336.207 & $321.184,292.145,92.050$ & n.d. & n.i. \\
\hline (VII) & 350.223 & $335.199,292.145,92.049$ & n.d. & n.i. \\
\hline (VIII) & 352.238 & $337.215,252.114,92.050$ & n.d. & 2-methyl-3-heptyl prodiginine* \\
\hline
\end{tabular}

*Identification based on comparison with published data by Setiyono et al. (2020).

n.d., not detected, n.i., not identified.

Chemical identities of (I) and (II) were further confirmed by ${ }^{1}$ H-NMR (Supplementary Figures 1, 2) and UPLC-MS and MS/MS [including (III), Supplementary Figures 6-8] analysis.

prodiginines in crude extracts of the CCA H. reinboldii from which we originally isolated P. rubra (cf. Petersen et al., 2021).

Cycloprodigiosin (I) induced full settlement (attachment and metamorphosis) in L. purpurea larvae at a significant level of $44.4 \% \pm 15.7(p=0.034, n=3)$ using a concentration of $0.2 \mu \mathrm{g}$ $\mathrm{mL}^{-1}$ At $0.1 \mu \mathrm{g} \mathrm{mL}^{-1}$ of (I) all larvae continued swimming while at $0.3 \mu \mathrm{g} \mathrm{mL}^{-1}$ of (I) all were found dead after $48 \mathrm{~h}$ (Figure 1B). All larvae that had not settled in response to (I) nor to other extracts/fractions of \#1783, including CE, DCM and Fr.8, were still actively swimming. In contrast, the pure fractions of prodigiosin (II) and 2-methyl-3-hexyl prodiginine (III), both at a concentration of $0.2 \mu \mathrm{g} \mathrm{mL}^{-1}(n=3)$, had a negative effect on the coral larvae since all died/disintegrated within the first $24 \mathrm{~h}$. However, lower concentrations of (II) (i.e., $0.1 \mu \mathrm{g} \mathrm{mL}^{-1}$ ) did neither harm the tested coral larvae nor induce any kind of settlement (see Figure 1B). Higher concentrations of (II) (i.e., $0.3 \mu \mathrm{g} \mathrm{mL}^{-1}$ ) have not been tested since the lower concentration was already lethal to the larvae. In addition, $0.1 \mu \mathrm{g}$ $\mathrm{mL}^{-1}$ of (III) was not applied due to limited availability of coral larvae. Note, all settlement-inducing extracts/fractions that included cycloprodigiosin (I) resulted in full settlement and not a single coral larva showed metamorphosis in the water column without prior attachment to the surface. On the other hand, the $\mathrm{MeOH}$ negative control (15 $\mu \mathrm{L} \mathrm{MeOH}$ added and evaporated, container filled up with $5 \mathrm{~mL}$ FASW, $n=3$ ) showed no signs of settlement and all tested larvae continued to swim actively over the entire length of the experiment. The positive controls (live CCA) induced $77.8 \% \pm 15.7(p=0.034, n=3)$ settlement in L. purpurea larvae, but some larvae died upon exposure to live CCA (see Figure 1B).

\section{Stability of the Photosensitive Pigment Cycloprodigiosin}

During cultivation, cultures of \#1783 grown on agar plates for $12 \mathrm{~h}$ in complete darkness and subsequently for $12 \mathrm{~h}$ under constant white light quickly lost their characteristic dark-red color upon light exposure but retained it if straightaway kept in darkness for $24 \mathrm{~h}$. Comparative MS analyses revealed the distinct presence of the prodiginines (I, II, and III) in cultures kept in darkness but showed a rapid decrease of the red pigments in cultures exposed to white light (cf. Supplementary Figure 10). In addition, while handling CE of \#1783 or any fraction or pure compound containing the pigments (I, II, and III), it was quite noticeable that their red color quickly faded upon light exposure as well. That is, we performed a degradation experiment in which a total amount of $1 \mu \mathrm{g}(0.2 \mu \mathrm{g} \mathrm{mL}-1 \times 5 \mathrm{~mL})$ of cycloprodigiosin (I) was exposed to three different light regimes (cf. Figure 2) in a setup similar to the previous settlement experiments: (i) complete darkness, (ii) constant white light and (iii) $12 \mathrm{~h}$ alternating periods of dark and light phases starting with complete darkness. After $24 \mathrm{~h}$ in complete darkness, the concentration of (I) dropped from initially $18.0 \mathrm{ng} \pm 0.6$ down to $8.1 \mathrm{ng} \pm 1.1$ but stayed somewhat stable at $6.0 \mathrm{ng} \pm 0.8$ until the end of the darkness experiment (Figure 2A). In contrast, after $24 \mathrm{~h}$ of exposure to constant white light the initial concentration of (I) dropped from $16.1 \mathrm{ng} \pm 0.6$ down to $0.7 \mathrm{ng} \pm 0.2$ and stayed at almost $0 \mathrm{ng}$ until the end of the light experiment (Figure 2B). The alternating light-regimes experiment instead revealed that after the first $12 \mathrm{~h}$ in complete darkness the concentration of (I) stayed quite stable (from initially $17.3 \mathrm{ng} \pm 0.7$ down to $14.8 \mathrm{ng} \pm 0.9$ ), however, after further $12 \mathrm{~h}$ of exposure to white light ( $24 \mathrm{~h}$ in total), the concentration of (I) dropped down to $1.8 \mathrm{ng} \pm 0.4$ and stood slightly above $0 \mathrm{ng}$ until the end of the experiment (Figure 2C).

\section{Importance of Light in Coral Settlement}

The obvious sensitivity of cycloprodigiosin (I) toward light led us to repeated settlement experiments using (I) and larvae of L. purpurea exposed to the latter mentioned three different light regimes. Two concentrations, 0.2 and $0.3 \mu \mathrm{g} \mathrm{mL} \mathrm{m}^{-1}$ (reviewed in pre-experiments) were used to test the settlementinducing activity of (I) on coral larvae under complete darkness (Figure 3A), constant white light (Figure 3B) and alternating light periods starting with complete darkness (Figure 3C). Changes in the moving behavior or in the shape and form of coral larvae to the morphogenic cue were examined every $12 \mathrm{~h}$ under a dissecting microscope. After $12 \mathrm{~h}$ in complete 
darkness (Figure 3A), 100\% $(p=0.025)$ of larvae attached in response to $0.2 \mu \mathrm{g} \mathrm{mL}^{-1}$ of (I) while only $33.3 \% \pm 24.9$ larvae attached in response to $0.3 \mu \mathrm{g} \mathrm{mL}^{-1}$ (the remaining larvae had dissolved). For the higher concentration of (I) this lethal trend proceeded and after $36 \mathrm{~h}$, all larvae had dissolved/died. After $24 \mathrm{~h}$ at a concentration of $0.2 \mu \mathrm{g} \mathrm{mL}-1,66.7 \% \pm 24.9$ $(p=0.037)$ of the attached larvae started metamorphosis while the remaining attached larvae had died. At $36 \mathrm{~h}$ and the final $48 \mathrm{~h}$, more settled recruits died and solely $33.3 \% \pm 24.9$ of them were still alive and within the process of metamorphosis in response to $0.2 \mu \mathrm{g} \mathrm{mL}^{-1}$ of (I). In comparison, no larvae died in response to (I) under constant light exposure (see Figure 3B). After $12 \mathrm{~h}, 20 \%$ ( $p=0.025)$ of all larvae performed attachment in response to $0.2 \mu \mathrm{g} \mathrm{mL}^{-1}$ of (I) whereas $53.3 \% \pm 18.9$ $(p=0.034)$ attached in response to $0.3 \mu \mathrm{g} \mathrm{mL}^{-1}$. In contrast to the complete darkness experiment, higher concentrations of (I) in the constant light experiments resulted in higher settlement rates $(73.3 \% \pm 9.4, p=0.034)$ than using the lower concentrations (33.3\% $\pm 9.4, p=0.034)$ after $48 \mathrm{~h}$. However, the highest coral larvae settlement rates were achieved by using a combination of (I) at a concentration of $0.2 \mu \mathrm{g} \mathrm{mL}^{-1}$ and $12 \mathrm{~h}$ alternating periods of dark and light phases starting with complete darkness. Thus, the latter alternating light experiment imitates the natural night and day cycle of a coral-reef environment (see Figure 3C). After $12 \mathrm{~h}$ of complete darkness, most coral larvae attached at a high and significant level in response to $0.2 \mu \mathrm{g} \mathrm{mL}-1$ of (I) $(86.7 \% \pm 9.4, p=0.034)$ and the unattached larvae were still alive and swimming. $12 \mathrm{~h}$ later, at full light $(24 \mathrm{~h}$ in total), all previously attached larvae had started already their metamorphosis. At the end of the experiment after $48 \mathrm{~h}$, $86.7 \% \pm 9.4(p=0.034)$ of $L$. purpura larvae had undergone full settlement. In contrast, the higher concentration of (I) $\left(0.3 \mu \mathrm{g} \mathrm{mL}^{-1}\right)$ showed a lethal effect for most larvae and only $40 \% \pm 32.7$ of coral larvae were attached. Similar to the settlement experiments in complete darkness (Figure 3A), all larvae had died after $48 \mathrm{~h}$ of alternating light conditions and disintegrated in response to the higher concentration of (I). The negative control showed no attachment or metamorphosis in all three light-regime experiments for the entire tested period of $48 \mathrm{~h}$. The highest rate of settlement behavior (attachment and/or metamorphosis) in the positive controls (live CCA) was achieved under complete darkness, resulting in $53.3 \% \pm 9.4(p=0.034)$ settlement and $13.3 \% \pm 9.4(p=0.034)$ attachment after $48 \mathrm{~h}$. Interestingly, the positive controls in the different light treatments caused varying mortalities in the tested coral larvae (see Figures 3A-C).

Figure 4 depicts the morphological changes within the settlement process of $L$. purpurea larvae exposed to the settlement inducer cycloprodigiosin (I) at $0.2 \mu \mathrm{g} \mathrm{mL}^{-1}$ (i.e., $1 \mu \mathrm{g}$ in $5 \mathrm{~mL}$ ) and $12 \mathrm{~h}$ alternating periods of dark and light phases starting with complete darkness. At the beginning of the settlement experiments, freshly collected planula larvae of L. purpurea (Figures 4A1,2) were added to the wells. On average, most coral larvae stopped their circular movement and attached to the bottom of the well already after $12 \mathrm{~h}$ (Figures 4B1,2). After $24 \mathrm{~h}$, first signs of metamorphosis were observed as most coral recruits started to develop a more pronounced oral disk. In the further course of coral settlement, the oral disk widened, and first signs of mesentery development was clearly visible, finally, after $48 \mathrm{~h}$, all attached coral recruits developed their typical "flowerlike" shape, containing six constrictions and a well-pronounced but narrow oral disk (Figures 4C1,2). Furthermore, coral recruits built-up a strong calcium carbonate skeleton and developed 6 to 12 functional tentacles (always a multiple of 6 ) after 4 weeks of the initial settlement. Figures 4D1,2 shows one of the fully developed coral polyps exactly 1 month after initial settlement.

\section{DISCUSSION}

Here we report the isolation and identification of a potent signaling molecule that reliably triggers the transition from freely swimming planula larvae into fully attached and metamorphosed polyps of the scleractinian coral L. purpurea. This morphogen has been identified as the dark-red pigment cycloprodigiosin (I) and was enriched and isolated from the crude extract of the CCAassociated, biofilm-building, obligate marine bacterium $P$. rubra \#1783 (Petersen et al., 2021). In contrast, crude extracts of other settlement-inducing biofilms investigated in our previous study triggered no settlement at the here tested concentration of $10 \mu \mathrm{g}$ $\mathrm{mL}^{-1}$. Instead, the latter extracts showed no effect and the larvae remained actively swimming throughout the entire $48 \mathrm{~h}$ of the experiment. This result may have multiple reasons such as: (a) the settlement-inducing compound was not extractable with the chosen method; (b) the tested concentration was not sufficient for larval settlement; (c) inducing biofilms, except for \#1783, may not rely on a chemical cue but rather on physical properties, e.g., micro surface structure and/or spectral elicitors (i.e., Doropoulos et al., 2016; Yusuf et al., 2019). However, this should be addressed in future studies, as there is currently insufficient evidence to verify any of these possibilities.

Besides cycloprodigiosin, two structurally closely related compounds, prodigiosin (II) and the putative prodigiosin derivative 2-methyl-3-hexyl prodiginine (III, see Supplementary Figure 5) were detected, identified and fully isolated. Also, five structurally related compounds (IV-VIII) have been detected in the crude extract of $P$. rubra \#1783 (see Table 1) but were not chemically purified due to their low abundance. Instead, compound (III), (IV), and (VIII) were identified by comparing their exact mass $\left(\mathrm{MS}^{1}\right)$ and their mass fragmentation data $\left(\mathrm{MS}^{2}\right)$ with Setiyono et al. (2020), who detected these compounds in organic extracts of two different $P$. rubra strains isolated from seawater samples around Alor Island, Indonesia. To the best of our knowledge, compounds (V-VII) have not been identified before and thus might be novel prodiginine pigments produced by $P$. rubra \#1783. However, all purified (I-III) and detected (IV-VIII) red pigments are likely members of the prodiginine family, a group of highly bioactive alkaloids characterized by their common tripyrole skeleton (Williamson et al., 2006).

Although structurally closely related, only cycloprodigiosin (I) showed a positive settlement effect on the coral larvae of L. purpurea. (I) was originally isolated from the marine bacterium Alteromonas rubra (Gerber and Gauthier, 1979) and its correct chemical structure was assigned a few years later (Gerber, 1983; Laatsch and Thomson, 1983). It has shown strong antimicrobial 
activity against several bacterial strains as well as against the pathogenic yeast Candida albicans (Lee et al., 2011) and might be of use as a potent immunosuppressant (Kawauchi et al., 1997). However, to the best of our knowledge, this is the first study demonstrating the potent settlement-inducing activity of cycloprodigiosin (I) for larvae of a scleractinian coral. The highest success rate in coral settlement was established by using (I) at a concentration of $0.2 \mu \mathrm{g} \mathrm{mL}^{-1}$ and applying an alternating $12 \mathrm{~h}$ dark/light cycle, resulting in $86.7 \% \pm 9.4(p=0.034)$ full settlement of $L$. purpurea larvae after $48 \mathrm{~h}$ (see Figure 3C). In comparison, the success rate of larvae settlement on live CCA (Figures 3A-C), normally used as positive control (Negri et al., 2001; Tebben et al., 2011, 2015; Sneed et al., 2014; Nietzer et al., 2018; Moeller et al., 2019), was with 53.3\% \pm 41.1 under a $12 \mathrm{~h}$ alternating dark/light cycle remarkably lower and thus highlights the potential value of (I) as a morphogenic cue. Not only was the metamorphosis on live CCA less predictable compared to (I), but we also observed that the settlement process on live CCA was delayed, since a few coral larvae were still at the level of attachment after 48 h (cf. Figures 3A-C). In general, we observed that $L$. purpurea larvae were extremely sensitive to small variations in the concentration of (I). Interestingly, under constant light exposure (see Figure 3B), a slightly higher concentration of $0.3 \mu \mathrm{g} \mathrm{mL} \mathrm{m}^{-1}$ of (I) was needed to achieve the second highest settlement rate in this study $(73.3 \% \pm 9.4$, $p=0.034$ ). These results may be explained by the recognized sensitivity of (I) to light (cf. Figures 2A-C). (I) is far more stable in complete darkness but quickly degrades upon the exposure to light. Therefore, at full light condition, a higher concentration of (I) may be needed, due to a rapid decomposition of this lightsensitive pigment. On the other hand, under complete darkness the concentration of 0.2 and particularly $0.3 \mu \mathrm{g} \mathrm{mL}^{-1}$ of (I) resulted in an overall higher larval mortality (see Figure 3A). The latter findings suggest that the treatment with (I) in complete darkness may be toxic to $L$. purpurea larvae while an exposure to (I) under constant light diminishes its bioactive capacity, due to the light-enhanced decomposition (see Figure 2), before coral larvae are able to attach to the surface or finalize their metamorphosis. In this study, a concentration of $0.2 \mu \mathrm{g}$ $\mathrm{mL}^{-1}$ of (I) combined with $12 \mathrm{~h}$ alternating periods of dark and light phases, thereby imitating the natural night and day cycle, achieved the highest settlement rate, approaching 90\%. By performing comparative statistics, we evaluated the effect size (Cohen's d) of our two most successful treatments and could show that the dark-light cycle at $0.2 \mu \mathrm{g} \mathrm{mL}^{-1}$ had a larger effect $(d=1.419)$ on coral settlement than the constant light treatment at $0.3 \mu \mathrm{g} \mathrm{mL} \mathrm{m}^{-1}$. Long-term observation of L. purpurea recruits of up to 1 month further strengthened the usefulness cycloprodigiosin for lasting coral settlement without negative effects on polyp morphology and physiology (cf. Figure 4).

Cycloprodigiosin hydrochloride is known for its strong anticancer activity against various cancer cell lines but has also shown general cytotoxicity against human HeLa cells already at concentrations as low as $1 \mu \mathrm{M}$ (Kamata et al., 2000; Yamamoto et al., 2000a,b). Thus, the concentrations of the free base (I) used in this study $\left(0.2\right.$ and especially $0.3 \mu \mathrm{g} \mathrm{mL}^{-1}$ or 622 and
$933 \mathrm{nM}$, respectively) might be responsible for the observed toxicity on the tested coral larvae, especially under constant dark conditions. The mechanisms underlying the biological activities of (I) are still unclear, however, many studies reported that cycloprodigiosin acts as a $\mathrm{H}^{+} / \mathrm{Cl}^{-}$symporter that can lower intracellular $\mathrm{pH}$ by acidification of the cytosol, but also raise $\mathrm{pH}$ in acidified organelles (Yamamoto et al., 1999, 2000a; Kamata et al., 2000). As shown by Yamamoto et al. (2000a,b) this pHregulating mechanism is concomitantly linked with the induction of apoptosis in cancer cells. However, if this process is likely involved in the settlement-inducing activity or the observed toxicity of (I) toward L. purpurea larvae (especially during dark treatments, see Figure 3A) remains yet to be deciphered.

The alternating $12 \mathrm{~h}$ dark and light cycle assay showed that the concentration of (I) in the first hours is crucial for a successful attachment of coral larvae to the surface. We assume that the following light period is a critical step to disable the presumed cytotoxicity of (I) toward coral larvae and thus ensures their successful cascaded settlement (Figures 2C, 3C). Previous research has shown that light intensity and quality as well as spectral cues such as color (e.g., reddish plastic surfaces) can determine the spatial distribution of coral recruits (Maida et al., 1994; Mundy and Babcock, 1998; Strader et al., 2015; Yusuf et al., 2019). However, besides this work no studies have investigated the interactions between light intensities and corresponding purified chemical settlement cues. It is therefore of particular importance to further explore the decomposing effect of light on (I) and screen for possible byproducts of this reaction and their effect on coral larvae settlement. Moreover, a future study could investigate the settlement dynamics between coral larvae, the morphogen (I) and different intensities of distinct light colors (i.e., blue, green or red light; $c f$. Strader et al., 2015). Mason et al. (2011) as well as Foster and Gilmour (2016) found that coral larvae settled preferentially on red colored plastic tags compared to white or other colored tags, indicating that light spectra might be an important component during settlement for some larvae. However, we think that the red color did not play a prominent role for the coral larvae in our settlement experiments, as we found similar high settlement rates for the experiments conducted in complete darkness (Figure 3A) and light (Figure 3B). Furthermore, prodigiosin (II) and 2-methyl3-hexyl prodiginine (III) are also brightly red colored and did not induce larvae settlement, indicating cycloprodigiosin (I) as the chemical inducing cue, rather than a spectral cue from the red color, as suggested in the study of Mason et al. (2011).

In contrast to (I), compounds (II) (prodigiosin) and (III) (2-methyl-3-hexyl prodiginine) did neither induce attachment nor metamorphosis at the tested concentration $\left(0.2 \mu \mathrm{g} \mathrm{mL}^{-1}\right)$. In fact, the toxicity of (II) and (III) was significantly higher compared to (I). This distinction in settlement-inductive capacity is likely linked to the structural differences between the three prodigiosin derivatives. The cyclization of the otherwise linear alkyl chain to an isoindol moiety seems to be responsible for the inducing activity of (I) in contrast to (II) and (III). This structural feature also accounts for the earlier elution and thus the slightly more polar nature of (I) compared to (II) and (III) in the reversephase chromatography (see Supplementary Figure 5), although 
all three compounds were insoluble in water. During the first $24 \mathrm{~h}$ of the settlement assays, coral larvae were observed to actively swim in orbital circles on the bottom of the well, presumably gathering and incorporating the three tested prodiginines. At this point it remains unclear if larvae were not able to take up and/or further process (II) and (III) or if both compounds simply target other molecular species and mechanisms within the larvae, which resulted in higher larval mortality compared to (I). Adding to this, fractions that were dominated by (I) (i.e., crude extract) showed higher success rates in coral settlement compared to fractions that were dominated by (II) (see Supplementary Figure 5). However, interactions between the prodiginines can be synergistic or inhibiting but ultimately remain complex and yet to be deciphered.

From prodigiosin (II) it was reported that this compound exhibited high antifouling activity against biofilm formation of Alteromonas sp. at $50 \mu \mathrm{g} \mathrm{mL} \mathrm{mL}^{-1}$ and negatively affected settlement of the barnacle Balanus amphitrite at $100 \mu \mathrm{g} \mathrm{cm}^{-2}$ (Priya et al., 2013). It has been suggested that prodigiosin (II) can cause RNA and DNA cleaving through oxidative damage by hydrogen peroxide $\left(\mathrm{H}_{2} \mathrm{O}_{2}\right)$ and hydroxyl radical generation, ultimately leading to an altered biofilm integrity of Pseudomonas aeruginosa (Kimyon et al., 2016). However, the producing strain of (I)-(III), P. rubra \#1783, belongs to a bacterial genus that is known to produce metabolites with manifold activities, including antibacterial and antifouling compounds (Holmström et al., 2002; Bowman, 2007; Offret et al., 2016). More specifically, these bacteria have demonstrated antibiotic activity against several coral pathogens, including Vibrio coralliilyticus and $V$. shiloi (Kvennefors et al., 2012), Serratia marcescens (Ritchie, 2006) and Thalassomonas loyana (Nissimov et al., 2009). Additionally, Pseudoalteromonas spp. have often been reported to induce settlement (attachment and/or metamorphosis) in larvae of scleractinian corals (Negri et al., 2001; Tebben et al., 2011, 2015; Tran and Hadfield, 2011; Sneed et al., 2014) and other marine invertebrates (Huang and Hadfield, 2003; Huggett et al., 2006). Given these insights, it appears plausible that highly vulnerable coral larvae may actively search for bacteria like $P$. rubra because of their rich supply of bioactive secondary metabolites that induce settlement, kill potential pathogens and/or reduce settlement of competitors.

The first and only other bacterial derived settlement cue was described by Tebben et al. (2011). These authors isolated tetrabromopyrrole (TBP), a water-soluble secondary metabolite, from a CCA-associated Pseudoalteromonas sp. that triggered metamorphosis (mostly without prior attachment) in larvae of the coral Acropora millepora. In contrast, Sneed et al. (2014) reported that TBP induced full settlement in larvae of the corals Porites astreoides, Orbicella franksi and Acropora palmata, however, only on low to moderate levels in the latter two coral species. In comparison to TBP, cycloprodigiosin (I) induced full settlement (i.e., attachment and metamorphosis) in coral larvae at very high settlement rates approaching $90 \%$. The high settlement rates could be also in part based on their physico-chemical characteristics. Water-insoluble cues such as (I) tend to adhere to the substrate surface which might increase the probability for an organized attachment before larval metamorphosis. Several studies on the settlement behavior of marine invertebrate larvae in response to different neurotransmitters demonstrated that the processes of attachment and metamorphosis may not necessarily be coupled and that both phenomena may require distinct chemical stimuli (Iwao et al., 2002; Grasso et al., 2011; Moeller et al., 2019). In the reef environment, a combination of bioactive cues likely allows for widespread larval settlement of various coral taxa and facilitation of coral settlement on a global scale rather than a single cue. Compared to (I), more water-soluble compounds such as TBP have the disadvantage to dissolve and rapidly dilute away from its point or origin (e.g., bacterial biofilm). However, these water-borne compounds may hold the advantage to signal habitat suitability toward searching coral larvae. In contrast, water-insoluble compounds such as (I) have the natural benefit to locally accumulate in settlement-inducing concentrations, thus enabling efficient attachment and metamorphosis at a favorable place. Additional environmental parameters such as light intensity may further diversify settlement mechanisms and, therefore, enhance settlement success rates of coral recruits.

Nonetheless, the ecological significance of (I) remains to be deciphered. Initial results using $\mathrm{MB}$ agar plates overgrown with P. rubra \#1783 for $24 \mathrm{~h}$ showed that $1 \mathrm{~cm}^{2}$ of monospecies biofilm yielded $25.2 \mu \mathrm{g} \pm 3.8$ of (I) while 4 and $9 \mathrm{~cm}^{2}$ resulted in $87,4 \mu \mathrm{g} \pm 29.3$ and $237.2 \mu \mathrm{g}$ of (I), respectively (cf. Supplementary Figures 4A,B). Knowing that $1 \mu \mathrm{g}$ of (I) applied to the bottom of a $5 \mathrm{~mL}$ well $\left(0.2 \mu \mathrm{g} \mathrm{mL} \mathrm{mL}^{-1}\right)$ induced full settlement in L. purpurea larvae and assuming that P. rubra \#1783 produces comparable amounts of (I) in the natural environment, it would only take approx. $4 \mathrm{~mm}^{2}$ surface-associated and monospecific biofilm of this bacterium for sufficient induction of coral larvae settlement. However, future studies should investigate the frequency of occurrence of P. rubra in CCA-associated biofilms and evaluate the natural concentration of (I) present in those bacterial assemblages.

In conclusion, the present study provided new insights into the putatively large variety of bacteria-derived coral settlement cues. We were able to demonstrate that the water-insoluble secondary metabolite cycloprodigiosin (I), produced by the CCA-associated bacterium $P$. rubra \#1783, reliably triggers complete settlement in larvae of the brooding scleractinian coral L. purpurea at high and significant levels, resulting in fully developed polyps (see Figures $4 \mathrm{D1}, 2$ ). That is, a combination of (I) and an alternating $12 \mathrm{~h}$ dark and light cycle enhanced settlement success rates to almost $90 \%$, thus highlighting the complex interplay between the morphogenic pigment and spectral cues. Future studies will enlighten the mode of action and molecular mechanisms underlying the inductive activity of (I) in combination with light intensity and frequency within the complex coral settlement process.

\section{DATA AVAILABILITY STATEMENT}

The original contributions presented in the study are included in the article/Supplementary Material, further inquiries can be directed to the corresponding author/s. 


\section{AUTHOR CONTRIBUTIONS}

L-EP, MYK, SN, and PJS designed the project. L-EP did literature review and initial writing of the manuscript and performed the bacterial growth experiments and the settlement assays. L-EP and MYK conducted the purification assays, structure elucidation as well as quantification of target compounds. L-EP and SN conducted the larval acquisition. SN maintained the aquarium facilities. MYK, SN, and PJS reviewed and edited the manuscript. All authors contributed to the article and approved the submitted version.

\section{FUNDING}

This study was carried out in the framework of the Ph.D. research training group "The Ecology of Molecules" (EcoMol) supported by the Lower Saxony Ministry for Science and Culture. PJS also acknowledge funding by the Deutsche Forschungsgemeinschaft

\section{REFERENCES}

Bowman, J. P. (2007). Bioactive compound synthetic capacity and ecological significance of marine bacterial genus Pseudoalteromonas. Mar. Drugs 5, 220 241. doi: $10.3390 / \mathrm{md} 504220$

Cohen, J. (1992). A power primer. Psychol. Bull. 112, 155-159. doi: 10.1037/00332909.112.1.155

Da-Anoy, J. P., Villanueva, R. D., Cabaitan, P. C., and Conaco, C. (2017). Effects of coral extracts on survivorship, swimming behavior, and settlement of Pocillopora damicornis larvae. J. Exp. Mar. Bio. Ecol. 486, 93-97. doi: 10.1016/j. jembe.2016.10.006

Doropoulos, C., Roff, G., Bozec, Y.-M., Zupan, M., Werminghausen, J., and Mumby, P. J. (2016). Characterizing the ecological trade-offs throughout the early ontogeny of coral recruitment. Ecol. Monogr. 86, 20-44. doi: 10.1890/150668.1

Erwin, P. M., Song, B., and Szmant, A. M. (2008). Settlement behavior of Acropora palmata planulae: effects of biofilm age and crustose coralline algal cover. Proc. 11th Int. Coral Reef Symp. 24, 1219-1224.

Erwin, P. M., and Szmant, A. M. (2010). Settlement induction of Acropora palmata planulae by a GLW-amide neuropeptide. Coral Reefs 29, 929-939. doi: 10.1007/ s00338-010-0634-1

Foster, T., and Gilmour, J. P. (2016). Seeing red: coral larvae are attracted to healthy-looking reefs. Mar. Ecol. Prog. Ser. 559, 65-71. doi: 10.3354/meps11902

Gerber, N. N. (1983). Cycloprodigiosin from Beneckea gazogenes. Tetrahedron Lett. 24, 2797-2798. doi: 10.1016/S0040-4039(00)88026-0

Gerber, N. N., and Gauthier, M. J. (1979). New prodigiosin-like pigments from Alteromonas rubra. Appl. Environ. Microbiol. 37, 1176-1179. doi: 10.1128/aem. 37.6.1176-1179.1979

Gleason, D. F., Edmunds, P. J., and Gates, R. D. (2006). Ultraviolet radiation effects on the behavior and recruitment of larvae from the reef coral Porites astreoides. Mar. Biol. 148, 503-512. doi: 10.1007/s00227-005-0098-y

Gleason, D. F., and Wellington, G. M. (1995). Variation in UVB sensitivity of planula larvae of the coral Agaricia agaricites along a depth gradient. Mar. Biol. 123, 693-703. doi: 10.1007/BF00349112

Grasso, L. C., Negri, A. P., Fôret, S., Sainta, R., Hayward, D. C., Miller, D. J., et al. (2011). The biology of coral metamorphosis: molecular responses of larvae to inducers of settlement and metamorphosis. Dev. Biol. 353, 411-419. doi: 10.1016/j.ydbio.2011.02.010

Harrington, L., Fabricius, K., De'Ath, G., and Negri, A. (2004). Recognition and selection of settlement substrata determine post-settlement survival in corals. Ecology 85, 3428-3437. doi: 10.1890/04-0298

Heyward, A. J., and Negri, A. P. (1999). Natural inducers for coral larval metamorphosis. Coral Reefs 18, 273-279. doi: 10.1007/s003380050193
(DFG) for the last instrument grant INST 184/147-1FUGG for the high-resolution mass spectrometer Waters Synapt G2-Si.

\section{ACKNOWLEDGMENTS}

The authors would like to thank Sven Rohde for the assistance in statistical analysis, Laura Fiegel for providing photographs of the coral settlement process and Julian Küppers for performing NMR measurements. The authors would also like to thank the reviewers for their valuable comments which helped to improve the manuscript.

\section{SUPPLEMENTARY MATERIAL}

The Supplementary Material for this article can be found online at: https://www.frontiersin.org/articles/10.3389/fmars. 2021.749070/full\#supplementary-material

Holmström, C., Egan, S., Franks, A., McCloy, S., and Kjelleberg, S. (2002). Antifouling activities expressed by marine surface associated Pseudoalteromonas species. FEMS Microbiol. Ecol. 41, 47-58. doi: 10.1111/j.1574-6941.2002.tb00965.x

Huang, S., and Hadfield, M. G. (2003). Composition and density of bacterial biofilms determine larval settlement of the polychaete Hydroides elegans. Mar. Ecol. Prog. Ser. 260, 161-172. doi: 10.3354/meps260161

Huggett, M. J., Williamson, J. E., de Nys, R., Kjelleberg, S., and Steinberg, P. D. (2006). Larval settlement of the common Australian sea urchin Heliocidaris erythrogramma in response to bacteria from the surface of coralline algae. Oecologia 149, 604-619. doi: 10.1007/s00442-006-0470-8

Iwao, K., Fujisawa, T., and Hatta, M. (2002). A cnidarian neuropeptide of the GLWamide family induces metamorphosis of reef-building corals in the genus Acropora. Coral Reefs 21, 127-129. doi: 10.1007/s00338-002-0219-8

Kamata, K., Okamoto, S., Oka, S., Kamata, H., Yagisawa, H., and Hirata, H. (2000). Cycloprodigiosin hydrochloride suppresses tumor necrosis factor (TNF) $\alpha$ induced transcriptional activation by NF-кB. FEBS Lett. 507, 74-80. doi: 10. 1016/S0014-5793(01)02946-5

Kawauchi, K., Shibutani, K., Yagisawa, H., Kamata, H., Nakatsuji, S., Anzai, H., et al. (1997). A possible immunosuppressant, cycloprodigiosin hydrochloride, obtained from Pseudoalteromonas denitrificans. Biochem. Biophys. Res. Commun. 237, 543-547. doi: 10.1006/bbrc.1997.7186

Kimyon, Ö, Das, T., Ibugo, A. I, Kutty, S. K., Ho, K. K., and Tebben, J. (2016). Serratia secondary metabolite prodigiosin inhibits Pseudomonas aeruginosa biofilm development by producing reactive oxygen species that damage biological molecules. Front. Microbiol. 7:972. doi: 10.3389/fmicb.2016. 00972

Kitamura, M., Koyama, T., Nakano, Y., and Uemura, D. (2007). Characterization of a natural inducer of coral larval metamorphosis. J. Exp. Mar. Biol. Ecol. 340, 96-102. doi: 10.1016/j.jembe.2006.08.012

Kitamura, M., Schupp, P. J., Nakano, Y., and Uemura, D. (2009). Luminaolide, a novel metamorphosis-enhancing macrodiolide for scleractinian coral larvae from crustose coralline algae. Tetrahedron Lett. 50, 6606-6609. doi: 10.1016/j. tetlet.2009.09.065

Kuffner, I. B. (2001). Effects of ultraviolet (UV) radiation on larval settlement of the reef coral Pocillopora damicornis. Mar. Ecol. Prog. Ser. 217, 251-261. doi: $10.3354 /$ meps 217251

Kvennefors, E. C. E., Sampayo, E., Kerr, C., Vieira, G., Roff, G., and Barnes, A. C. (2012). Regulation of bacterial communities through antimicrobial activity by the coral holobiont. Microb. Ecol. 63, 605-618. doi: 10.1007/s00248-0119946-0

Laatsch, H., and Thomson, R. H. (1983). A revised structure for cycloprodigiosin. Tetrahedron Lett. 24, 2701-2704. doi: 10.1016/S0040-4039(00)87981-2 
Lee, J. S., Kim, Y.-S., Park, S., Kim, J., Kang, S. J., Lee, M.-H., et al. (2011). Exceptional production of both prodigiosin and cycloprodigiosin as major metabolic constituents by a novel marine bacterium, Zooshikella rubidus S1-1. Appl. Environ. Microbiol. 77, 4967-4973. doi: 10.1128/AEM.01986-10

Maida, M., Coll, J. C., and Sammarco, P. W. (1994). Shedding new light on scleractinian coral recruitment. J. Exp. Mar. Biol. Ecol. 180, 189-202. doi: 10. 1016/0022-0981(94)90066-3

Maru, N., Inuzuka, T., Yamamoto, K., Kitamura, M., Schupp, P. J., Yamada, K., et al. (2013). Relative configuration of luminaolide. Tetrahedron Lett 54, 4385-4387. doi: 10.1016/j.tetlet.2013.05.143

Mason, B., Beard, M., and Miller, M. W. (2011). Coral larvae settle at a higher frequency on red surfaces. Coral Reefs 30, 667-676. doi: 10.1007/s00338-0110739-1

Moeller, M., Nietzer, S., and Schupp, P. J. (2019). Neuroactive compounds induce larval settlement in the scleractinian coral Leptastrea purpurea. Sci. Rep. 9:2291. doi: 10.1038/s41598-019-38794-2

Morse, D. E., Hooker, N., Morse, A. N. C., and Jensen, R. A. (1988). Control of larval metamorphosis and recruitment in sympatric agariciid corals. J. Exp. Mar. Biol. Ecol. 116, 193-217. doi: 10.1016/0022-0981(88)90027-5

Morse, D. E., and Morse, A. N. C. (1991). Enzymatic characterization of the morphogen recognized by Agaricia humilis (scleractinian coral) larvae. Biol. Bull. 181, 104-122. doi: 10.2307/1542493

Mundy, C. N., and Babcock, R. C. (1998). Role of light intensity and spectral quality in coral settlement: implications for depth-dependent settlement?. J. Exp. Mar. Biol. Ecol. 223, 235-255. doi: 10.1016/S0022-0981(97)00167-6

Negri, A. P., Webster, N. S., Hill, R. T., and Heyward, A. J. (2001). Metamorphosis of broadcast spawning corals in response to bacteria isolated from crustose algae. Mar. Ecol. Prog. Ser. 223, 121-131. doi: 10.3354/meps22 3121

Nietzer, S., Moeller, M., Kitamura, M., and Schupp, P. J. (2018). Coral larvae every day: Leptastrea purpurea, a brooding species that could accelerate coral research. Front. Mar. Sci. 5:466. doi: 10.3389/fmars.2018.00466

Nissimov, J., Rosenberg, E., and Munn, C. B. (2009). Antimicrobial properties of resident coral mucus bacteria of Oculina patagonica. FEMS Microbiol. Lett. 292, 210-215. doi: 10.1111/j.1574-6968.2009.01490.x

Nozawa, Y. (2008). Micro-crevice structure enhances coral spat survivorship. J. Exp. Mar. Biol. Ecol. 367, 127-130. doi: 10.1016/j.jembe.2008.09.004

Offret, C., Desriac, F., Le Chevalier, P., Mounier, J., Jégouand, C., and Fleury, Y. (2016). Spotlight on antimicrobial metabolites from the marine bacteria Pseudoalteromonas: chemodiversity and ecological significance. Mar. Drugs 14:129. doi: 10.3390/md14070129

Petersen, L.-E., Moeller, M., Versluis, D., Nietzer, S., Kellermann, M. Y., and Schupp, P. J. (2021). Mono- and multispecies biofilms from a crustose coralline alga induce settlement in the scleractinian coral Leptastrea purpurea. Coral Reefs 40, 381-394. doi: 10.1007/s00338-021-02062-5

Price, N. (2010). Habitat selection, facilitation, and biotic settlement cues affect distribution and performance of coral recruits in French Polynesia. Oecologia 163, 747-758. doi: 10.1007/s00442-010-1578-4

Priya, K. A., Satheesh, S., Ashokkumar, B., Varalakshmi, P., Selvakumar, G., and Sivakumar, N. (2013). "Antifouling activity of prodigiosin from estuarine isolate of Serratia marcescens CMST 07," in Microbiological Research In Agroecosystem Management, ed. R. Velu (Heidelberg: Springer), 11-21.

Ritchie, K. B. (2006). Regulation of microbial populations by coral surface mucus and mucus-associated bacteria. Mar. Ecol. Prog. Ser. 322, 1-14. doi: 10.3354/ meps322001

Ritson-Williams, R., Arnold, S. N., Fogarty, N. D., Steneck, R. S., Vermeij, M. J. A., and Paul, V. J. (2009). New perspectives on ecological mechanisms affecting coral recruitment on reefs. Smithson. Contrib. Mar. Sci. 38, 437-457. doi: 10. 5479/si.01960768.38.437

Ritson-Williams, R., Arnold, S. N., Paul, V. J., and Steneck, R. S. (2014). Larval settlement preferences of Acropora palmata and Montastraea faveolata in response to diverse red algae. Coral Reefs 33, 59-66. doi: 10.1007/s00338-013$1113-2$

Ritson-Williams, R., Paul, V. J., Arnold, S. N., and Steneck, R. S. (2010). Larval settlement preferences and post-settlement survival of the threatened Caribbean corals Acropora palmata and A. cervicornis. Coral Reefs 29, 71-81. doi: 10.1007/s00338-009-0555-z
Setiyono, E., Adhiwibawa, M. A. S., Indrawati, R., Prihastyanti, M. N. U., Shioi, Y., and Brotosudarmo, T. H. P. (2020). An indonesian marine bacterium, Pseudoalteromonas rubra, produces antimicrobial prodiginine pigments. ACS Omega 5, 4626-4635. doi: 10.1021/acsomega.9b04322

Sneed, J. M., Sharp, K. H., Ritchie, K. B., and Paul, V. J. (2014). The chemical cue tetrabromopyrrole from a biofilm bacterium induces settlement of multiple Caribbean corals. Proc. R. Soc. B. Biol. Sci. 281:20133086. doi: 10.1098/rspb. 2013.3086

Strader, M. E., Davies, S. W., and Matz, M. V. (2015). Differential responses of coral larvae to the colour of ambient light guide them to suitable settlement microhabitat. R. Soc. Open Sci. 2:150358.

Tebben, J., Motti, C. A., Siboni, N., Tapiolas, D. M., Negri, A. P., Schupp, P. J., et al. (2015). Chemical mediation of coral larval settlement by crustose coralline algae. Sci. Rep. 5:10803. doi: 10.1038/srep10803

Tebben, J., Tapiolas, D. M., Motti, C. A., Abrego, D., Negri, A. P., Blackall, L. L., et al. (2011). Induction of larval metamorphosis of the coral Acropora millepora by tetrabromopyrrole isolated from a Pseudoalteromonas bacterium. PLoS One 6:e19082. doi: 10.1371/journal.pone.0019082

Tran, C., and Hadfield, M. G. (2011). Larvae of Pocillopora damicornis (anthozoa) settle and metamorphose in response to surface-biofilm bacteria. Mar. Ecol. Prog. Ser. 433, 85-96. doi: 10.3354/meps09192

Vermeij, M. J. A., Marhaver, K. L., Huijbers, C. M., Nagelkerken, I., and Simpson, S. D. (2010). Coral larvae move toward reed sounds. PLoS One 5:e10660. doi: 10.1371/journal.pone.0010660

Webster, N. S., Smith, L. D., Heyward, A. J., Watts, J. E. M., Webb, R. I., Blackall, L. L., et al. (2004). Metamorphosis of a scleractinian coral in response to microbial biofilms. Appl. Environ. Microbiol. 70, 1213-1221. doi: 10.1128/AEM. 70.2.1213-1221.2004

Wellington, G. M., and Fitt, W. K. (2003). Influence of UV radiation on the survival of larvae from broadcast-spawning reef corals. Mar. Biol. 143, 1185-1192. doi: 10.1007/s00227-003-1150-4

Williamson, N. R., Fineran, P. C., Leeper, F. J., and Salmond, P. C. (2006). The biosynthesis and regulation of bacterial prodiginines. Nat. Rev. Microbiol. 4, 887-899. doi: 10.1038/nrmicro1531

Yamamoto, C., Takemoto, H., Kuno, K., Yamamoto, D., Tsubura, A., Kamata, K., et al. (1999). Cycloprodigiosin hydrochloride, a new $\mathrm{H}+/ \mathrm{Cl}-$ symporter, induces apoptosis in human and rat hepatocellular cancer cell lines in vitro and inhibits the growth of hepatocellular carcinoma xenografts in nude mice. Hepatology 30, 894-902. doi: 10.1002/hep.510300417

Yamamoto, D., Kiyozuka, Y., Uemura, Y., Yamamoto, C., Takemoto, H., Hirata, H., et al. (2000a). Cycloprodigiosin hydrochloride, a $\mathrm{H}+/ \mathrm{Cl}-$ symporter, induces apoptosis in human breast cancer cell lines. J. Cancer Res. Clin. Oncol. 126, 191-197. doi: 10.1007/s004320050032

Yamamoto, D., Uemura, Y., Tanaka, K., Nakai, K., Yamamoto, C., Takemoto, H., et al. (2000b). Cycloprodigiosin hydrochloride, $\mathrm{H}(+) / \mathrm{CL}(-)$ symporter, induces apoptosis and differentiation in HL-60 cells. Int. J. Cancer 88, 121-128. doi: 10.1002/1097-0215(20001001)88:1

Yusuf, S., Zamani, N. P., Jompa, J., and Junior, M. Z. (2019). Larvae of the coral Acropora tenuis (Dana 1846) settle under controlled light intensity. IOP Conf. Ser. Earth Environ. Sci. 253:012023. doi: 10.1088/1755-1315/253/1/012023

Conflict of Interest: The authors declare that the research was conducted in the absence of any commercial or financial relationships that could be construed as a potential conflict of interest.

Publisher's Note: All claims expressed in this article are solely those of the authors and do not necessarily represent those of their affiliated organizations, or those of the publisher, the editors and the reviewers. Any product that may be evaluated in this article, or claim that may be made by its manufacturer, is not guaranteed or endorsed by the publisher.

Copyright $\odot 2021$ Petersen, Kellermann, Nietzer and Schupp. This is an open-access article distributed under the terms of the Creative Commons Attribution License (CC BY). The use, distribution or reproduction in other forums is permitted, provided the original author(s) and the copyright owner(s) are credited and that the original publication in this journal is cited, in accordance with accepted academic practice. No use, distribution or reproduction is permitted which does not comply with these terms. 